\title{
EVALUATE WITH RUBRICS IN STEM TRAINING THROUGH SOCIAL NETWORK
}

\author{
L.I. Hojas Hojas' ${ }^{1}$, E.M. García Del Toro', I. Hojas García-Plaza² \\ ${ }^{1}$ Universidad Politécnica de Madrid, ETS Ingeniería Civil (SPAIN) \\ ${ }^{2}$ Georg-August-Universität Gotingen (GERMANY)
}

\begin{abstract}
Regulated education requires that the level of learning acquired in the training process be assessed. In addition, it is convenient for all the agents that participate in the process to have cross-evaluations of the activities carried out.
\end{abstract}

Systems based on computer platforms incorporate assessment mechanisms in a simple and efficient way. In the field of education, the best known mechanism is the rubric-based procedure. The work is reduced to adapting the rubrics to the WhatsApp or Instagram type messaging applications.

The work we are doing is aimed at adapting these techniques to modularized teaching within training in the field of STEM (Science, Technology, Engineering and Mathematics).

The reason for focusing on this area of work is determined by the training plans that we are proposing at the Escuela de Ingeniería Civil of the Universidad Politécnica de Madrid.

Rubrics are a well-known work method that is very suitable for this project because it allows the evaluation of all the agents involved in the training process.

The evaluation in the future will develop dynamically. All agents will intervene in the process of evaluating the results achieved in the processes that are being implemented, but also in evaluating the processes and contents themselves.

This type of system, characterized by being open and flexible, is difficult to implement within the framework of the training processes regulated in many countries.

Rubrics are usually used to evaluate training content and work methodologies. But this mechanism must also be generalized to evaluate the proposed contents themselves and their relationship with the labor needs at all times.

Most of us only think about the student-teacher relationship, but the reality is more complex and it would be convenient to include at least the following figures: students, teachers, tutors, auditors, prescribers and managers of the training processes.

Training must be open and flexible and the intervention of all the aforementioned agents favors the achievement and improvement of the proposed results.

This text presents a proposal for the implementation and management mechanisms for different activities through the rubrics procedures.

Keywords: Modularization, ECTS, STEM, Training, Mobile Platforms, Training Networks, Whatsapp, Instagram.

\section{INTRODUCTION}

The COVID pandemic, like all crises, has had some positive effects. Among which it is worth highlighting: the adaptation of the training content to on-line systems, the creation of networks between students and teachers, the orientation of the work to synchronous-asynchronous systems and the devaluation of the exam as a form of supervision of the knowledge of students due to the difficulty of directly controlling the work being done

These elements were already known but their implementation was scarce and little appreciated by teachers in regulated teaching systems.

The pandemic has caused a radical change in teaching models, which most likely will no longer disappear. This change can be summarized in the following characteristics: 
- The training is oriented to carry out activities not exams

- Participation and the creation of working groups are fundamental elements

- The training process must be guided by criteria of efficiency

Among these, the third of the characteristics indicated in the previous paragraph stands out, since it is not very developed in the current educational framework

Education, like the economy, must be guided by productivity criteria. The concept of productivity[1] is the basis of modern economy and the optimization of results is based. That is, to achieve the best possible results with the least investment. This concept must be included in any type of regulated training so that professionals obtain the best results with the least effort

An understandable example that would illustrate well the concept of productivity applied to university education would be the use of computer tools[2] that allow us to do in a few hours what twenty years ago required more than a week of work

The training process has to be developed with advanced cognitive models similar to those that help us to carry out, for example, the design of computer processors, in order to optimize results

An added problem that arises in training activities is that the only viable way to model the process is the analysis of the results. It is a critical process within the training framework. Systems based on computer platforms[3] allow the incorporation of simple, fast and efficient assessment mechanisms

In this communication, and as a continuation of the one entitled Modularization of Engineering content adapted to social network, an evaluation method applied to training in the field of STEM (Science, Technology, Engineering and Mathematics) based on rubrics is proposed.

\section{METHODOLOGY}

In the model that currently prevails in most universities, the number of training units required to obtain an academic degree is very high, on the order of 250 units. In the proposed methodology, the work unit has a load equivalent, more or less, to 1 ECTS credit

The traditional way of evaluating has great shortcomings that we have tried to solve by proposing an evaluation method based on rubrics. [4] The rubric is assimilated to an evaluation matrix that incorporates in one axis the performance criteria of a task and in the other axis a scale and whose interior boxes are full of text. In each box of the rubric it is described what type of execution would be worthy of that degree of the scale. A very important element when evaluating the works is the public nature of both the works and the rubrics. In this way, students can know in advance the type of activities that are carried out, the average time that other students have needed to carry them out and the grades obtained for said work.

\subsection{Rubrics}

This public nature has many advantages, firstly it helps students to guide their activities and secondly it reduces the work carried out in a hasty manner since the student is aware of the long-term impact that poorly performed activities will have.

The choice of rubrics is a complicated process and its development will be dynamic and trying to optimize the processes. The three factors that we can use as a seed in the process are

- Deepening the work topic

- Quality of the presented result

- Links generated in the training process

With these three basic elements, it is possible to build rubric models with different degrees of depth as can you see in figure 1 : 


\section{Deepening of the activity}

\begin{tabular}{|l|r|}
\hline Deepening of the activity & $\mathbf{3}$ \\
Presentation of results & $\mathbf{5}$ \\
Collaboration and participation & $\mathbf{2}$ \\
\hline
\end{tabular}

Collaboration and participation

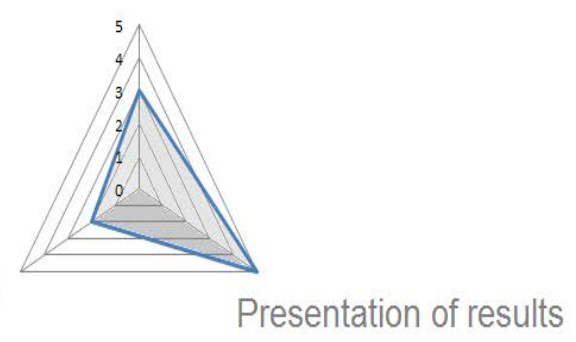

Figure 1: Simple model for the elaboration of a rubric.

\subsection{Agents}

There are four elements in the work network:

\section{Student}
a) Evaluator
b) Tutor
c) Organization

The student performs the work supervised by a tutor who acts as instructor and as supervisor of the work. [5] Students can carry out the activities individually or in teams, but also in a mixed way, which we will call coordinated.

Coordinated activities are those that a student or group of students develop knowing and collaborating with other students or other groups. The objective of these coordinated activities is to improve learning and collaboration processes.

On the other hand, the evaluators will have to indicate by means of rubrics the criteria that are evaluated and the evaluations that have been made to the different works presented.

This procedure allows both students and evaluators to follow the activities carried out, so that the results are shown in the most transparent way possible to all the agents who participate in the training process.

The tutor guides and supervises the activities but does not participate in the evaluation of these

Finally, the managing body of the organization, the University or any other managing body, supervises all those who intervene in the process, with the aim of favoring the development of the processes and solving the possible contingencies that may occur.

The system seeks to be in constant change, introduce new content, techniques or activities and analyze the impact by observing the repercussions that occur in the training process

The objective of modeling relationships using this 4-element Venn diagram[6] is to allow the management of the different conflicts that will occur in the development of the training process

The contact areas are the common work areas and therefore the areas where both work and collaboration relationships and conflicts will occur.

Developing models with a high level of participation and therefore with a high number of possible situations will only be manageable through the information of the processes.

\subsection{Application Procedure}

The development of experiences is essential to adjust work techniques.

At this moment we have two major training systems, on the one hand a regulated system, with a very important teaching load, oriented towards professional empowerment and developed mostly by young students, and on the other, lifelong training oriented on all to adults and with smaller teaching loads and above all more flexible both in the contents and in the implementation procedures. 
The proposal is to integrate both processes. It is very difficult to do it immediately and therefore it will be a gradual process and probably determined by professional activities and social networks.

Training is most likely the next big market for social networking systems.

The roles that we have indicated above: student, tutor, supervisor and manager will be flexible figures and in many cases we will participate in all of them.

Today I am a student, tomorrow I am a tutor or supervisor, and another day I will participate in the design and management of the activities.

The systems will be flexible and oriented towards open education throughout life.

\subsection{Objectives}

The objective is that education is a means both for our professional and social fulfillment. We will train in the areas that interest us, adequately our teaching loads to our needs and availability. The goal is to get visible results for others. The objective is to know, develop and disseminate the achievements of our training process. Another very important aspect is the creation of work networks with all the agents. Training has to be a means of socialization because that way we will improve our quality of life and our work.

Rubrics are the means by which others value our work and we value theirs. And they have to be flexible and dynamic multi-criteria systems.

The models for the rubrics in education should be understood as they are already being used in other applications based on social networks and where the score of the agents optimizes the processes, already common examples can be Uber or Airbnb among many others.

The rubrics serve to contrast our activities with others and thus see the degree of acceptance that our work has.

The procedure by rubrics with several criteria will serve to have a general knowledge obtaining average or detailed values, punctually, when you want to access a specific activity.

\subsection{Methods}

Transformation of working methods is likely to take place over the next decade, and different organizations will come and go.

It will be necessary to establish networks with content, with tutors and evaluators and a developed management institutions.

Work ideas are currently under development, we usually include them in Open Education systems.

The integration of Regulated training and continuous training is a necessity to improve the efficiency and adaptation of workers.

In several European projects financed by the European Social Fund, experiences have been carried out on the use of the new platforms for continuous training (ADAPT[7], TESMES[8], BETEL[9] and TOTEL[10]) and the integration with the new terminals (MTM[11] project of the $V$ Framework program) that we have developed in our work team.

The construction of platforms for both Learning Content Management System (LMCS) and Learning Management System (LMS) are a necessity because a large part of the teaching activity is to make training materials that are already prepared and found on the Internet.

Platforms such as Coursera[12] and Edx [13]are two good examples of the training resources available, to which must be added the large number of videos, podcast and blogs that already have a large number of training resources available e some very high quality cases.

The use of platforms such as Moodle, already common in training and communication and messaging tools, is a structure already developed for the large-scale process of activities.

The last important element is the methodological work tools aimed at efficiency in the training processes.

In the organization of production processes, the use of AGIL methods is frequent. 
Agile methods have been developed for project management, initially from computer systems, but can be adapted to training with similar results.

The main characteristics of this type of methodologies are:

- Flexible development

- Adaptation to culture and social environment

- Facilitate planning

- Facilitate communication

Some experiences developed with Scrum are highly recommended because it integrates the training activity with the work techniques in organizations.

The SCRUM methodology is oriented to regular deliveries, with partial results -sprint- and iterative processes.

These techniques allow us to integrate the modules that we have proposed of 1 ECTS in the regulated teaching units, subjects, of between 3 and 6 ECTS credits.

The work of tutoring and supervision are integrated into this type of work techniques. The rubrics appear immediately and is a part of the processes of these methodologies.

This methodology has developed the fundamental elements that are very suitable for the training processes:

- Reviews

- Follow-up meeting schedule

- Retrospectives

In summary, a list of the advantages obtained for all the agents of the training process are:

- Facilitate the planning of tasks and objectives

- Reduction and Control of working times

- Reduction of conflicts or inefficiencies

- Introduction of process management metrics

Social Networks Social networks applied to training will very efficiently facilitate all these aspects that we have discussed. In the work we have done with the end-of-degree projects, we have seen that the results obtained are satisfactory. In several documents we have presented these results.... Articles... An example has been the development of the TFGs aimed at entrepreneurship, which has allowed the introduction of the different techniques and to evaluate through the TRLs the degree of maturity of the activities developed in the projects

The analysis of the data, both in its positive and negative aspects, will provide the evaluation of the students, but also of the teachers, tutors and the organization itself.

The goal of this model is the dynamic adjustment of the elements of evaluation, certifications and accreditations through the use of the data generated in the training process. Since the training of the future will be developed in an open, flexible and dynamic way and all the agents will intervene in the optimization process of the educational system.

In this way the student will be able to build their curriculum with the set of activities carried out and the different rubrics that have been obtained so that their best qualities can be known in a way that is oriented to the selection process that is being carried out.

\section{RESULTS}

The process of adapting teaching methodologies in STEM areas to the 21 st century society is gradual.

Our work has evolved during the last 25 years, first it was the introduction of communications technologies based on TCP / IP in the 90s, the introduction of mobile systems of the PDA type, for example en the project Multimedia Terminal Mobile (MTM[11] project of the V Framework program), the frequent use of modular units in non-regulated training and currently the process of adapting regulated study programs to new modular methodologies. 
In these years we have developed training experiences in projects oriented to entrepreneurship and in the use of platforms.

Finally, the COVID pandemic has caused a forced immersion in these techniques of regulated teaching and an intensive immersion in the use of social networks both for the relationship between teachers and students and between students.

At this time, training social networks are being introduced in an accelerated way, academic centers oriented to face-to-face teaching have the difficulty of our great inertia at all levels, both organizational, teaching staff and even in some cases of students.

The results obtained by modularizing the activities, opening the training processes and in general using the mass media and socialization are being positive

\section{CONCLUSIONS}

Training must change to adapt to the level of changes in today's society.

The training process has to gain efficiency at university levels and integrate continuous training throughout life.

The evaluation of the training processes is essential to know the achievements obtained in learning and has to be public and reciprocal, so all the intervening agents such as students, tutors, evaluators and the organization itself must know the situation.

The assessment elements must respond to several parameters, the first group is determined by the level of depth in the work topic, the second by the quality of the results presented and finally the third by the work network that has been established.

The ability to give answers with a good knowledge of the problem and well documented is very important, but also the ability to create work groups and networks for collaboration and participation.

\section{REFERENCES}

[1] Morales Sandoval C, Masis Arce A. La Medicion de la Productividad del Valor Agregado: una aplicación empírica en una cooperativa agroalimentaria de Costa Rica (Measuring value added productivity: an empirical aplication in an agroalimentary cooperative in Costa Rica). TEC Empres 2014;8:41. doi:10.18845/te.v8i2.1988.

[2] Minaya Rodriguez, F. Hojas Hojas, I. García del toro Eva M., Pérez Chamizo R. Caja de Herramientas Formativas. XVI Foro Int. sobre Evaluación la Calid. la Educ. Super. y la Investig., Santiago de Compostela: 2019, p. 100.

[3] Hojas Hojas, L. García del Toro E. BM-Learning experience in carring out final Degree Proyects. ICERI 2020 Proc., Sevilla: IATED Academy; 2020.

[4] Cano García E. Las rúbricas como instrumento de evaluación de competencias en Educación Superior: ¿Uso o abuso? Profesorado Rev Currículum y Form Profr 2015;19:265-80.

[5] Hojas Hojas I. Garcia del Toro E.. Final degree projects ad a tool for innovations and entrepreneurshipNo Title. EDULEARN20 Proc., 2020, p. 8786-8793,. doi:10.21125/edulearn.2020.2172.

[6] Juan F, Nacional U, Rica DC, Rica C, Nacional U, Rica DC, et al. Lógica y teoría de conjuntos mediante diagramas de Venn - Euler por sectores 2019:185-91.

[7] European Commission. Evaluation of the Employment and ADAPT Community InitiativesNo Title 2000. https://cordis.europa.eu/article/id/9428-evaluation-of-the-employment-and-adaptcommunity-initiatives.

[8] Hojas Hojas I.. Servicios telemáticos para PYMES. Madrid: 1998.

[9] Hojas Hojas I.. Bética Telecomunicaciones (BETEL). Madrid: 2001.

[10] Hojas Hojas I.. Toledo Telecomunicaciones TOTEL. Madrid: 2001.

[11] Hojas Hojas I.. Multimedia Terminal Mobile (MTM). Madrid: 2000. 
[12] Daphne Koller and Andrew Ng. COURSERA 2020. https://www.coursera.org/ (accessed November 20, 2020).

[13] Agawalr A. EDEX 2020. https://www.edX.org/ (accessed November 18, 2020). 